\title{
O BEM JURÍDICO PROTEGIDO PELA LEI N. 9.613 DE 1988: primeiras críticas
}

\author{
THE LEGALLY PROTECTED INTEREST BY ACT N. 9.613/98: first critics
}

Vivian Cristina Schorscher ${ }^{1}$

\begin{abstract}
Resumo:
Este trabalho apresenta e reexamina criticamente a controvérsia em torno da identificação do bem jurídico efetivamente protegido pelas normas de combate à lavagem de dinheiro. A necessidade de um novo estudo a esse respeito destacase especialmente quando analisadas as alternativas defendidas pela doutrina que alcançam desde o bem jurídico do crime antecedente, a administração da justiça e a ordem econômica como um todo, até a teoria de tratar-se, nestas leis, de um delito pluriofensivo. A fim de permitir uma análise que não se limite ao plano teórico, neste trabalho vinculam-se as teses estudadas com a realidade brasileira e, portanto, com a Lei n. 9.613, de 03 de março de 1998. Analisam-se as propostas acima mencionadas, problematizando as soluções que oferecem e buscando alternativas a estas, e encerrase o presente trabalho com uma primeira crítica ao simbolismo penal que pode ser identificado nas leis de combate à lavagem de dinheiro.

Palavras-chave: Lavagem de dinheiro. Bem jurídico. Crime antecedente. Administração da justiça. Ordem econômica. Simbolismo penal.
\end{abstract}

\begin{abstract}
:
This paper presents and reexamines the discussion regarding the identification of the legal interest actually protected by the laws enacted to fight against money laundering critically. The need for a new study of this subject is set forth specially in view of the analysis of the alternatives defended in theory, which reach from the legal interest protected by the predicate offense, the administration of justice and the economical order as a whole to the thesis according to which these laws create a "plurioffensive" crime. In order to enable an analysis which is not strictly limited to theory, this paper relates the studied theories to Brazilian reality, and, therefore, with Act n. 9.613, of March $3^{\text {rd }}, 1998$. The abovementioned suggestions are analyzed and the solutions they propose are questioned, in the search of alternatives. The present paper ends with a first criticism to the penal symbolism which may be identified in the laws enacted for the fight against money laundering.
\end{abstract}

Keywords: Money laundering. Legally protected interest. Predicate offense. Administration of justice. Economical order. Penal symbolism.

\section{Introdução}

A partir da Segunda Guerra Mundial, a sociedade globalizada, pósindustrial, deparou-se com problemas decorrentes da crescente ampliação das redes de

1 Doutoranda em Direito Penal pela Faculdade de Direito da Universidade de São Paulo e pesquisadora na Escola de Direito de São Paulo. 
organizações criminosas internacionais dedicadas, inicialmente, ao contrabando e, mais especificamente a partir da década de 80 , ao tráfico de entorpecentes e outros crimes tidos como particularmente graves. A ampliação e profissionalização da criminalidade estruturada e organizada passaram a exercer efeitos cada vez mais temidos na vida econômica dos diversos Estados, diante da possível contaminação de ramos inteiros de atividade e de um eventual controle do poder político através da corrupção. Da mesma maneira, instalou-se correspondente temor no âmbito da vida privada, onde a consciência da existência de verdadeiras sociedades e associações criminosas (e não mais somente quadrilhas) criou um sentimento coletivo de insegurança cada vez maior.

Esse sentimento, identificado inicialmente por Ulrich $\mathrm{Beck}^{2}$ ao definir a chamada sociedade de risco, determinou o surgimento de vigorosa reivindicação popular, a demandar que os governos passassem a combater a criminalidade de modo efetivo. Essa reivindicação dirigia-se, sobretudo, àquelas condutas tidas como crimes especialmente organizados e nocivos, tais como o tráfico de entorpecentes ou de armas. Assim, iniciou-se um movimento de criminalização mundial, com a edição de normas penais cada vez mais específicas e agravadas, conforme o caso concreto que mais abalasse ou prejudicasse a sociedade em determinado momento.

No entanto, apesar do agravamento das penas cominadas ao cometimento de crimes tidos como tipicamente praticados pela criminalidade organizada, esta continuou a sua expansão e seu florescimento global, levando os Estados, por um lado, a sentir a necessidade de atuar em concerto, a fim de inibir e combater tais organizações e, por outro lado, provocando o surgimento e desenvolvimento, como novum, do conceito da prevenção e criminalização da lavagem de dinheiro. Inicialmente, este crime foi idealizado para combater especificamente o narcotráfico; ${ }^{3}$ no entanto, logo se passou a entender que os mesmos princípios deveriam ser aplicados com igual rigor a vários outros crimes (ou até mesmo a todos). ${ }^{4}$ Isso decorreu do reconhecimento de que os Estados não estavam

2 BECK, Ulrich. La sociedad del riesgo: hacia una nueva modernidad. Tradução de J. Navarro, D. Jiménez, M. R. Borrás. Barcelona: Paidós, 1998. p. 25 ss.

3 V. Convenção das Nações Unidas contra o Tráfico Ilícito de Entorpecentes e Substâncias Psicotrópicas, adotada em 19 de dezembro de 1988.

4 Com a finalidade de ampliar as frentes de combate à lavagem de dinheiro, as sete maiores potências do mundo (G-7) criaram, em 1990, o "Financial Action Task Force on Money Laundering" (FATF), ou Grupo de Ação Financeira sobre o Branqueamento de Capitais (GAFI), um órgão intergovernamental para a promoção de políticas de combate à lavagem de dinheiro e financiamento do terrorismo. Foi no exercício dessas funções que o GAFI elaborou as Quarenta Recomendações, publicadas inicialmente em abril de 1990, e atualizadas em 1996 e em 2003, nas quais determina que todo crime grave deveria ser tido como antecedente à lavagem de dinheiro. Mais recentemente, a Convenção das Nações Unidas contra o Crime Organizado Transnacional, de 2003, buscou estabelecer uma cooperação mais eficaz no combate à criminalidade organizada transnacional 
logrando combater os graves delitos que passaram a ser considerados como crimes antecedentes à lavagem de dinheiro, atividade que, em si, pode ser tida como meramente derivada da conduta prévia. Conforme simplifica José de Faria Costa: "só há necessidade de 'branquear' dinheiro se ele provier de atividades primitivamente ilícitas". 5

Um dos objetivos principais declarados pelos idealizadores dos diplomas legais voltados à prevenção e ao combate desse crime - e reconhecidos pela doutrina como central da problemática ${ }^{6}$-, era o isolamento dos criminosos. Estes deveriam ser separados da sociedade e do mercado lícito de tal maneira que se vissem impedidos de infiltrar os seus ganhos ilegítimos na economia formal. Essa tática levaria a que os crimes definidos como antecedentes à lavagem de dinheiro deixassem de ser rentáveis para os seus praticantes. Pretendia-se, portanto, desmantelar as organizações criminosas através do corte de seu abastecimento financeiro. ${ }^{7}$

Uma vez iniciados a prevenção e o combate ao crime de lavagem de capitais, os Estados começaram a reconhecer os caminhos usualmente trilhados pelos criminosos objetivando a "lavagem" de seus ganhos. Assim, foi editada uma série de normas sobre os controles a serem implementados pelas instituições financeiras para obstarem a contratação de seus serviços com o intuito de instrumentalizar a lavagem de valores de origem obscura, bem como definidas várias medidas restritivas relativamente aos chamados paraísos fiscais, as quais passaram a ser impostas por organismos internacionais, tais como, por exemplo, o Grupo de Ação Financeira sobre o Branqueamento de Capitais (GAFI).

e, conseqüentemente, também à lavagem de dinheiro, propondo um conceito de criminalidade organizada e reiterando a necessidade de combater a sua alimentação financeira. Merecem ser ressaltadas, ainda, as Diretivas da União Européia relativas ao combate à lavagem de dinheiro: a primeira, adotada em 1991, apenas buscava reprimir expressamente o narcotráfico; a segunda, adotada em 2001, ampliou o rol de crimes antecedentes para todos aqueles considerados como graves, e a terceira, adotada em 2005, ampliou as exigências de cooperação de agentes da iniciativa privada.

5 COSTA, José de Faria. O branqueamento de capitais: algumas reflexões à luz do direito penal e da política criminal). In: CORREIA, Eduardo, et al. Direito penal económico europeu: Textos doutrinários. Problemas especiais. Coimbra: Coimbra Editora, 1999. v. 2, p. 308-309.

6 Nesse sentido, M. Maiwald afirma que, em geral, a finalidade do tipo ("Tatbestand") da lavagem de dinheiro é definida como consistente em impedir a infiltração de bens e valores adquiridos por meios ilegais no ciclo lícito da economia, verbis: "Der Zweck des Tatbestands besteht darin, das Einschleusen illegal erworbener Vermögensgegenstände in den legalen Wirtschaftskreislauf zu verhindern”. (MAIWALD, Manfred. Auslegungsprobleme im Tatbestand der Geldwäsche. In: WEIGEND, T.; KÜPPER, G. (Orgs.). Festschrift für Hans Joachim Hirsch zum 70. Geburtstag am 11. april 1999. Berlim / Nova Iorque: Walter de Gruyter, 1999. p. 633.).

V. também RYDER, Barry. The crusade against money laundering. In: Politica Criminal, Derechos Humanos y Sistemas Jurídicos en el Siglo XXI. Volumen de homenaje al prof. Dr. Pedro R. David en su 72. aniversario (21/7/1929). Buenos Aires: Depalma, 2001. p. 685.

7 Cf. Id. Ibid., p. 682-683. 
Atualmente, contudo, diante do fato de que, por um lado, a prevenção e o combate à lavagem de dinheiro tal como imaginados não têm apresentado o sucesso esperado, e, por outro lado, considerando que as alterações normativas ampliaram os horizontes da definição dessa conduta típica de tal maneira que a distanciaram expressivamente dos objetivos iniciais relacionados ao seu combate, faz-se necessário examinar com maior profundidade a controvérsia em torno da identificação do bem jurídico efetivamente protegido pelas normas de prevenção e combate à lavagem de dinheiro.

Essa relevância resta ainda mais clara quando analisadas as alternativas apresentadas e defendidas pela doutrina, que alcançam desde o bem jurídico do crime antecedente, a administração da justiça e a ordem econômica como um todo, até a teoria de tratar-se, esta nova figura, de um delito pluriofensivo, cujo bem jurídico englobaria um número variável dentre as alternativas anteriores e outras ${ }^{8}$. Percebe-se, portanto, que, conforme a posição adotada, a lavagem de dinheiro deixaria de ser uma conduta a ser analisada no âmbito do Direito Penal econômico, não-obstante grande parte da doutrina - assim como sua própria denominação - indicar essa classificação.

Uma vez estabelecida a relevância da identificação do bem jurídico do crime de lavagem de dinheiro, contudo, ressalta-se que este trabalho não perderá de vista o fato de que referido conceito apenas constitui um instrumento prático dentro da realidade social, a qual, por sua vez, é caracterizada por sua dinamicidade. Por essa razão, procurarse-á ultrapassar essa indagação inicial para ir mais além, efetuando uma análise da relação social que se produz no mundo fático, uma vez que, consoante Juan Bustos Ramirez, “o que se protege, em definitivo, é essa relação social". ${ }^{9}$

A fim de permitir uma análise que não se limite ao plano teórico, neste trabalho buscar-se-á vincular as teses estudadas com a realidade brasileira, e, portanto,

\footnotetext{
8 Vidales Rodríguez y Palma Herrera, por exemplo, afirmam que o crime de lavagem de capitais atinge tanto o bem jurídico administração da justiça quanto ordem econômica (Cf. COBO DEL ROSAL, Manuel; LÓPEZGÓMEZ, Carlos Zabala. Blanqueo de capitales: abogados, procuradores y notarios, inversores, bancarios y empresarios (Repercusión en las leyes españolas de las nuevas directivas de la Comunidad Europea) (Estudio doctrinal, legislativo y jurisprudencial de las infracciones y de los delitos de blanqueo de capitales). Madrid: CESEJ, 2005. p. 93).

Por sua vez, L. G. Pinheiro afirma que este delito atinge os bens jurídicos administração da justiça, a segurança geral da comunidade (uma vez que o crime de lavagem de dinheiro incrementa os delitos prévios), os bens jurídicos antecedentes, embora estes apenas de forma mediata, e a economia em geral (PINHEIRO, Luís Goes. O branqueamento de capitais e a globalização: facilidades na reciclagem, obstáculos à repressão e algumas propostas de política criminal. Revista Portuguesa de Ciência Criminal, Coimbra, v. 12, n. 4, p. 603648, out./dez. 2002. p. 642-643.)

9 BUSTOS RAMÍREZ, Juan. Política criminal e injusto política criminal, bem jurídico, desvalor do ato e do resultado. Tradução de J. Sérgio Fragoso. Revista de Direito Penal, Rio de Janeiro, n. 29, p. 38-54, jan./jun. 1980. p. 50.
} 
tendo em vista as disposições da legislação vigente neste País, qual seja, a Lei n. 9.613, de 03 de março de 1998 (Lei n. 9.613/1998).

\section{O Bem Jurídico no Crime de Lavagem de Dinheiro}

De modo geral, a doutrina é assente em afirmar, conforme o faz Manuel da Costa Andrade, que a tutela de bens jurídicos simultaneamente define a função do Direito Penal e os limites dentro dos quais a sua intervenção se legitima. ${ }^{10}$ Ainda assim, não se pode perder de vista que a importância atribuída ao conceito de bem jurídico varia conforme e é influenciada pela forma adotada na organização de cada Estado - naturalmente, nãosomente sua relevância no estabelecimento da função do Direito Penal, mas também seu real poder limitador do poder punitivo estatal será diferente em Estados Democráticos, Social e Democráticos ou Autoritários, assim como sofrerá influência da cultura local em cada Estado. ${ }^{11}$

Igualmente, por mais que a doutrina reconheça repetidamente que ainda não se alcançou um conceito inequívoco e plenamente válido de bem jurídico para todas as situações enfrentadas pelo Direito Penal, parte-se do pressuposto de que "o ponto de partida do tipo penal está no bem jurídico compreendido como de valor vital para a comunidade e para a auto-realização do indivíduo", ${ }^{12}$ o que é reconhecido como válido desde o Iluminismo, momento histórico a partir do qual se firmou a tese de que o Direito Penal foi criado e desenvolvido como forma de proteger bens da vida tidos como particularmente importantes numa sociedade em determinado momento histórico.

Atualmente, contudo, deve-se ter em vista a distinção conceitual que surgiu com a emergência da importância dos bens jurídicos difusos nas sociedades, entre os quais se destacam, por exemplo, os relacionados às áreas econômica, ambiental e do consumo. ${ }^{13}$ Nesse sentido, o “bem jurídico idealizado sob uma perspectiva individual repousa naquelas

\footnotetext{
${ }^{10}$ ANDRADE, Manuel da Costa. A nova lei dos crimes contra a economia (Dec.-Lei n. 28/84, de 20 de janeiro) à luz do conceito de "bem jurídico". In: CORREIA, Eduardo, et al. Direito penal económico europeu: textos doutrinários. Problemas gerais. Coimbra: Coimbra Editora, 1998. v. 1, p. 389.

No mesmo sentido, v. entre outros, LIBERATI, Wilson Donizeti. Bem jurídico-penal e constituição. In: LOPES, Maurício Antonio Ribeiro; LIBERATI, Wilson Donizeti (Orgs.). Direito penal e constituição. São Paulo: Malheiros, 2000. p. 175; BUSTOS RAMÍREZ, Juan. op. cit., p. 44-45.

11 SILVEIRA, Renato de Mello Jorge. Direito penal supra-individual. São Paulo: Revista dos Tribunais, 2003. p. 52 .

12 PITOMBO, Antônio Sérgio A. de Moraes. Lavagem de dinheiro: a tipicidade do crime antecedente. São Paulo: Revista dos Tribunais, 2003. p. 66.

13 SILVEIRA, Renato de Mello Jorge. A construção crítica do bem jurídico espiritualizado e suas críticas fundamentais. Boletim IBCCrim, São Paulo, v. 10, n. 122, p. 14-15, jan. 2003. p. 14.
} 
situações em que se exija a maior proteção ofertada pelo Estado, em face da possibilidade de identificá-lo [o individual] (...). A situação é diversa, no entanto, quando se trata de bens de cunho difuso, em que o foco é centrado em uma massa não definida, situação na qual se faz necessária uma observação acurada do efeito lesivo em seus membros". ${ }^{14}$

Torna-se, portanto, imprescindível estabelecer qual o bem jurídico que o legislador visou proteger com a Lei n. 9.613/98, ainda mais diante da amplitude e indefinição do tipo penal em si, que levaram ao surgimento de diversas teorias doutrinárias acerca desta problemática controvérsia. Para tanto, ter-se-á em mente a clássica definição de bem jurídico apresentada por Hans Welzel, segundo quem este conceito abrange "um bem vital ou individual que, devido ao seu significado social, é juridicamente protegido(...). Bem jurídico é, pois, toda situação social desejada que o Direito quer garantir contra lesões." ${ }^{\prime 15 / 16}$

A maior parte da doutrina restringe a presente discussão em torno das seguintes alternativas: (i) o bem jurídico protegido seria o mesmo protegido pelo tipo penal definidor do crime antecedente, sendo, portanto, objeto de uma "superproteção"; (ii) o bem jurídico protegido seria a administração da justiça em geral; e (iii) o bem jurídico protegido seria a ordem econômica nacional e/ou internacional. ${ }^{17}$

${ }^{14}$ SILVEIRA, Renato de Mello Jorge. Direito penal supra-individual. cit., p. 53.

${ }^{15}$ WELZEL, H. Das deutsche Strafrecht. 11. ed. Berlim: Walter de Gruyter, 1969. p. 4. Apud LIBERATI, Wilson Donizeti. op. cit., p. 169.

${ }^{16}$ Não se ignora a existência de várias outras propostas, entre as quais as positivistas, sociológicas, de cunho funcionalista, e as teorias consitucionais, conforme destaca LIBERATI, Wilson Donizeti. op. cit., p. 168-172.

17 Diferentemente, R. Hefendehl apresenta uma análise crítica de número maior de possíveis bens jurídicos, incluindo, além dos ora estudados, a tarefa estatal nacional de afastar os efeitos de ações delitivas, a segurança interna do Estado, além de detalhar mais entretidamente as diversas facetas que a administração da justiça poderia assumir enquanto bem jurídico protegido pelas Legislações de prevenção e combate à lavagem de dinheiro. (HEFENDEHL, Roland. Kann und soll der Allgemeine Teil bzw. das Verfassungsrecht missglückte Regelungen des Besonderen Teils retten? Berlin: Walter de Gruyter, 2001. p. 150-153).

Similarmente, S. Barton afirma que o bem jurídico da legislação alemã de prevenção e combate à lavagem de dinheiro é a segurança interna, tanto do Estado alemão quanto de todos os outros Estados, sendo que o objetivo final da norma seria impedir o fortalecimento de organizações criminosas e o ataque futuro a outros bens jurídicos, perigo que corrói a segurança interna de todos os Estados. (BARTON, S. Sozial übliche Geschäftstätigkeit und Geldwäsche (§ 261 StGB). Strafverteidiger, ano 13, v. 3, p. 156-163, 1993. p. 160.)

V., também, KARGL, Walter. Probleme des Tatbestands der Geldwäsche (§ 261 StGB). Neue Justiz Zeitschrift für Rechtsprechung und Rechtsanwendung, ano 55, v. 2, p. 57-63, 2001. p. 60; BOTTKE, Wilfried. Teleologie und Effektivität der Normen gegen Geldwäsche (Teil 2). Zeitschrift für Wirtschaft - SteuerStrafrecht (WISTRA), ano 14, v. 4, p. 121-130, 15 de maio de 1995. p. 124.

V. Greco Filho, por seu turno, descreve que parte pequena da doutrina entende como bem jurídico atingido pela lavagem de dinheiro o patrimônio, em analogia ao tipo penal da receptação, criticando, no entanto essa opinião, como sendo uma visão muito estreita. (GRECO FILHO, Vicente. Tipicidade, bem jurídico e lavagem de valores. In: COSTA, José de Faria; Silva, Marco Antonio Marques da (Coords.). Direito penal especial, processo penal e direitos fundamentais: visão luso-brasileira. São Paulo: Quartier Latin, 2006. p. 161-162.) 
Há de se reconhecer, portanto, uma divisão doutrinária em torno deste problema reconhecidamente complexo, cuja discussão parte do questionamento acerca da própria existência de um interesse digno de proteção, ${ }^{18}$ assim como da dúvida sobre se este delito efetivamente protege um bem jurídico distinto dos bens jurídicos tutelados pelos crimes antecedentes. ${ }^{19}$

Especificamente no caso brasileiro, enfrenta-se, ainda, a dificuldade adicional de que não é possível a associação inicial automática do tipo penal da lavagem de dinheiro ao bem jurídico protegido pelo capítulo do Código Penal, no qual poderia ter sido inserto o dispositivo penal, o que decorre do fato de que esse crime foi introduzido em nosso sistema penal através de uma lei autônoma, seguindo o mesmo método escolhido pelos legisladores dos Estados Unidos da América, Colômbia, Chile e Equador. Diferentemente, vários países inseriram o tipo penal da lavagem de dinheiro em seus Códigos Penais. Assim o fizeram, por exemplo, a Alemanha, a França, a Itália e a Suíça. ${ }^{20}$ Deve-se notar, contudo, que mesmo quando a inovação legislativa é realizada através da inserção do novo tipo no Código Penal, nem por isso pode-se aceitar como incontroversa a identificação do bem jurídico protegido. ${ }^{21}$

\subsection{O bem jurídico como o mesmo do protegido pelo delito prévio}

Uma das interpretações apontadas pela doutrina afirma que a definição do bem jurídico protegido pela Lei n. 9.613/1998 deveria ser realizada com base na ofensa ao bem jurídico agredido pelo delito prévio, fundamentalmente, devido ao fato de que, para grande parte desses autores, a lavagem de dinheiro ser uma conduta decorrente da prática delitiva anterior.

Nesse caso, portanto, a incriminação da conduta daquele que venha a ocultar bens ou valores oriundos de uma das atividades criminosas antecedentes visaria, na verdade, ao combate dos delitos prévios. A lavagem de dinheiro, portanto, atingiria

\footnotetext{
18 Conforme assinala CALLEGARI, André Luís. Lavagem de dinheiro. São Paulo: Manole, 2004. p. 140.

19 Nesse sentido, conforme destaca ODON, Tiago Ivo. Lavagem de dinheiro: os efeitos macroeconômicos e o bem jurídico tutelado. Revista de Informação Legislativa, Brasília, v. 40, n. 160, p. 333-349, out./dez. 2003. p. 334, “a primeira questão que surge (...) é se o crime de lavagem é concebido a partir da análise de bens jurídicos tutelados pelas normas subjacentes aos crimes antecedentes ou se ele possui autonomia axiológica, um bem jurídico próprio".

${ }^{20} \mathrm{Na}$ Alemanha, o delito foi inserido no $§ 261$ do Código Penal; na França, nos arts. 222 a 238 do seu Código Penal de 1994, na Itália, no art. 648 bis de seu Código Penal, e na Suíça, no art. 305 de seu Código Penal. (v. CERVINI, Raúl; OLIVEIRA, Willian Terra; GOMES, Luiz Flávio. Lei de lavagem de capitais. São Paulo: Revista dos Tribunais, 1998. p. 191-198, 207-208, 211 e 215).

${ }^{21}$ Nesse sentido, v. COBO DEL ROSAL, Manuel; LÓPEZ-GÓMEZ, Carlos Zabala. op. cit., p. 92.
} 
o mesmo bem jurídico lesionado pelo crime antecedente. Tratar-se-ia, pois, de uma "superproteção" deste através da imposição de dificuldades adicionais na (re)utilização dos bens oriundos dos delitos prévios, com os quais, idealmente, o agente ficaria isolado.

De fato, pode-se afirmar que, por detrás da criminalização da lavagem de dinheiro, sempre existiu um objetivo maior e, ao mesmo tempo, pouco esclarecido pelos defensores da tipificação penal dessa conduta: assim, fala-se, em parte, do combate à criminalidade relacionada ao narcotráfico, em parte, do combate à criminalidade organizada. $^{22}$

Nesse mesmo sentido, Vicente Greco Filho aponta que não-só o crime de lavagem de dinheiro é mais um elo na cadeia dos crimes antecedentes, como ele é praticado justamente para ocultar e assegurar o seu proveito. No entendimento desse Autor, devido ao fato de a própria Lei n. 9.613/1998 estabelecer uma vinculação processual de competência para o julgamento do crime de lavagem de dinheiro, isso estaria a indicar "que o crime de lavagem acompanha o crime antecedente, não apenas no plano da competência, mas também no plano do direito material e tutela de bens jurídicos". ${ }^{23}$

Na doutrina européia, destaca-se a tese de Franz Salditt, ${ }^{24}$ que afirma que as normas de prevenção e combate à lavagem de dinheiro têm como objetivo banir da vida econômica os autores dos crimes antecedentes, mas que esse "banimento" não se daria para a proteção da economia, e sim, para evitar que a participação na economia lícita fortalecesse os criminosos, de tal modo a permitir que continuem suas atividades criminosas principais (os delitos prévios). Semelhante opinião é sustentada por Christian Burr, segundo quem o $§ 261$ do Código Penal alemão não contém um bem jurídico específico, prestando-se tão-somente à intensificação da proteção de bens jurídicos almejada pelos tipos definidos como antecedentes. ${ }^{25}$

Essa perspectiva encontrava respaldo à época do chamado "primeiro movimento de caracterização dos crimes antecedentes "26 (ao qual corresponde a primeira geração de leis incriminadoras da lavagem de dinheiro), quando o único delito cujos frutos

\footnotetext{
${ }^{22}$ MAIWALD, Manfred. Auslegungsprobleme im Tatbestand der Geldwäsche. In: WEIGEND, T.; KÜPPER, G. (Orgs.). Festschrift für Hans Joachim Hirsch zum 70. Geburtstag am 11. april 1999. Berlim / Nova Iorque: Walter de Gruyter, 1999. p. 633-634.

${ }^{23}$ GRECO FILHO, Vicente. op. cit., p. 162-163.

${ }^{24}$ SALDITT, Franz. Der Tatbestand der Geldwäsche. Strafverteidiger, v. 1, p. 121-136, 1992. p. 122.

25 BURR. Christian. Geldwäsche: Eine Untersuchung zu § 261 StGB. Siegburg: Schmitt, 1995. p. 27.

${ }^{26}$ PITOMBO, Antônio Sérgio A. de Moraes. Lavagem de dinheiro: a tipicidade do crime antecedente. São Paulo: Revista dos Tribunais, 2003. p. 73.
} 
podiam ser objeto de lavagem era o narcotráfico e, portanto, o bem jurídico tutelado seria (ou, pelo menos, poderia ser tido como sendo) a saúde pública.

Ademais, a Exposição de Motivos à Lei n. 9.613/1998 parece apontar nesse sentido ao indicar que um dos objetivos da Lei de Lavagem seria a proteção de todos os bens jurídicos dos delitos prévios. ${ }^{27}$ No entanto, a própria Exposição de Motivos, em seguida, acrescenta a defesa do Estado e da Economia aos objetivos e como fundamentos para a definição da autonomia da Lei n. 9.613/1998.

Outro argumento contrário a essa teoria de "superproteção" é o fato de que a Lei n. 9.613/1998 somente prevê uma pena para a conduta tipificada, independentemente do crime a partir do qual o objeto da lavagem de dinheiro seja obtido, sendo ela diferente da pena cominada aos diversos delitos prévios. ${ }^{28}$ Essa afirmativa, contudo, não se coaduna com a lição doutrinária segundo a qual a imposição da penalidade é conseqüência do valor próprio do bem, aliado à valoração que lhe é atribuída pela sociedade, a qual também justifica a proteção do bem, sendo isso reconhecido pelo legislador penal. ${ }^{29}$

Reforçando ainda mais a falta de sustentabilidade da tese ora em análise, deve-se ter em mente que, caso o objetivo das legislações antilavagem fosse uma "superproteção" do bem jurídico atingido pelo crime antecedente, a própria lavagem de dinheiro deveria, também, agravar a lesão específica a esse bem jurídico. Isso, no entanto, não ocorre em várias situações, como, por exemplo, no caso de lavagem de recursos oriundos do tráfico de entorpecentes: a criminalização do narcotráfico visa proteger o bem jurídico saúde pública, mas não é possível vislumbrar um agravamento da lesão por este bem sofrido em função do tráfico, através da lavagem dos ganhos auferidos em sua decorrência. ${ }^{30}$

Nesse sentido, também, a diferença entre a pena cominada ao crime de lavagem de dinheiro e, portanto, à retroalimentação do crime antecedente, seja para punir com maior gravidade, seja para punir mais levemente, também demonstra que se trata de crimes com bens jurídicos diversos, de valoração axiológica diferente. Do contrário, haveria infração direta ao princípio da proporcionalidade. ${ }^{31}$

\footnotetext{
${ }^{27}$ Exposição de Motivos n. 692, de 18.12.1996, publicada no Diário do Senado Federal, de 25.11.1997, p. 25.671 .

${ }^{28}$ Como exemplos podem ser citados o crime antecedente da extorsão mediante seqüestro, cuja pena cominada é maior do que a pena prevista para o crime de lavagem de dinheiro, ao passo que, no caso do crime de tráfico de armas, a pena prevista é inferior à pena cominada à lavagem de dinheiro.

29 PRADO, Luiz Regis. Bem jurídico-penal e constituição. São Paulo: Revista dos Tribunais, 1997. p. 21.

${ }^{30}$ HEFENDEHL, Roland. op. cit., p. 150.

31 ODON, Tiago Ivo. Lavagem de dinheiro: os efeitos macroeconômicos e o bem jurídico tutelado. Revista de Informação Legislativa, Brasília, v. 40, n. 160, p. 333-349, out./dez. 2003. p. 336-337.
} 
Adicionalmente, o confronto desta teoria com a pluralidade de delitos prévios leva o intérprete ao ponto de ser obrigado a sempre reconhecer a consunção do crime de lavagem de dinheiro pelo delito prévio, ${ }^{32}$ uma vez que, no limite, tratar-se-ia de mero exaurimento deste.

Essa teoria poderia levar, ainda, à criação de um falso dilema ao colocar em dúvida se a lavagem de dinheiro deveria ser penalizada com a finalidade de prevenir a comissão dos crimes antecedentes ou, ao revés, se a punição destes deveria ser realizada a fim de impedir a conduta típica da lavagem de dinheiro. ${ }^{33}$

Contudo, essa hipótese não procede e o eventual falso dilema conseqüentemente não ocorre, justamente porque os bens jurídicos tutelados são diversos: a atividade do agente do crime de lavagem de dinheiro não contribui para e não mantém o ataque anterior ao bem jurídico lesionado pela conduta prévia; portanto, sua atividade atinge outro bem jurídico o qual cumpre identificar. Não fosse este o caso, seria impossível punir o autor, cúmplice ou partícipe do crime antecedente pelo crime de lavagem de dinheiro, do mesmo modo verificado, por exemplo, no caso do crime de receptação (Código Penal, art. 180).

De qualquer forma, fica clara a necessidade de se estabelecer restrições à definição do bem jurídico protegido para evitar interpretações equivocadas como esta que, em última instância, acabaria por alçar o crime de lavagem de dinheiro a uma forma qualificada de receptação o que, indubitavelmente, não era o objetivo do legislador nacional (afirmação que encontra reforço, por exemplo, no próprio art. $2^{\circ}$, II, da Lei n. 9.613/1998, ${ }^{34}$ que determina a independência entre o processo e julgamento dos crimes antecedentes e do crime de lavagem) ou dos redatores das várias convenções internacionais firmadas para a contenção desta forma de criminalidade.

\subsection{A Administração da Justiça}

Outra parcela da doutrina afirma que o bem jurídico protegido pelas legislações de prevenção e combate à lavagem de dinheiro é a administração da justiça. Os defensores desse entendimento buscam alargar o conceito de administração da justiça,

${ }^{32}$ CALLEGARI, André Luís. Lavagem de dinheiro. cit., p. 144.

${ }^{33}$ PITOMBO, Antônio Sérgio A. de Moraes. op. cit., p. 74.

${ }^{34}$ Lei n. 9.613/1998 verbis: “Art. $2^{\circ}$. O processo e julgamento dos crimes previstos nesta Lei:

(...)

II - independem do processo e julgamento dos crimes antecedentes referidos no artigo anterior, ainda que praticados em outro país;" 
enquanto bem jurídico, de modo que este passe a abranger todas as expressões da Justiça para alcançar seus objetivos e finalidades. ${ }^{35}$

$\mathrm{Na}$ doutrina européia, os autores que sustentam essa opinião podem ser identificados e divididos em dois grupos: o primeiro grupo argumenta ser o bem jurídico tutelado a garantia do direito do Estado de confiscar bens obtidos através de determinados crimes antecedentes. Já o segundo grupo afirma que não há um bem jurídico diretamente tutelado, sendo que a criminalização da lavagem de dinheiro visa proporcionar, fundamentalmente, o maior número possível de meios para facilitar a identificação do núcleo da organização criminosa e seu posterior desmantelamento pelos órgãos investigatórios.

A primeira corrente mencionada é insustentável, tanto no Direito estrangeiro quanto em nosso sistema legal, face à existência de outros dispositivos que já asseguram tal direito de maneira direta e eficaz, como, por exemplo, o art. 91, II, "b”, do Código Penal brasileiro, ${ }^{36}$ que determina o confisco dos produtos do crime como conseqüência da condenação. ${ }^{37}$

Já o argumento apresentado pela segunda corrente doutrinária, relativo à função puramente instrumental da criminalização da lavagem de dinheiro face às dificuldades criadas pelos criminosos para o correto funcionamento da justiça através da ocultação dos bens oriundos da atividade criminosa, ${ }^{38}$ exige uma análise mais cautelosa: os defensores dessa opinião afirmam que o injusto do crime de lavagem de dinheiro apenas surge através da valorização especial de determinados crimes ou criminosos antecedentes.

Assim, o objetivo do novo tipo penal seria possibilitar às autoridades investigatórias a identificação do centro das organizações criminosas através da manutenção do chamado "rastro de papel", a indicar o caminho que as autoridades teriam de percorrer para alcançar os autores dos crimes antecedentes. ${ }^{39}$ Com isso, seria possível que atuassem de forma preventiva e inibissem as atividades criminosas de referidas organizações.

\footnotetext{
35 MAIA, Rodolfo Tigre. Lavagem de dinheiro (lavagem de ativos provenientes de crime): anotações às disposições criminais da Lei n. 9.613/98. São Paulo: Malheiros, 1999. p. 54.

${ }^{36}$ Igualmente, por exemplo, este direito é diretamente protegido pelo direito alemão, in casu, pelos $\S \S 73$ e ss. do StGB, motivo que justifica o baixo grau de filiação a esta posição doutrinária também na Alemanha.

37 Nesse sentido, v. HEFENDEHL, Roland. op. cit., p. 151.

${ }^{38}$ COBO DEL ROSAL, Manuel; LÓPEZ-GÓMEZ, Carlos Zabala. op. cit., p. 92.

39 Walter. Probleme des Tatbestands der Geldwäsche (\$261 StGB). Neue Justiz - Zeitschrift für Rechtsprechung und Rechtsanwendung, ano 55, v. 2, p. 57-63, 2001. p. 61.
} 
Contudo, a adoção dessa teoria levaria ao incremento ad absurdum da definição do Direito Penal como protetor de bens juridicamente relevantes, segundo Roland Hefendehl. ${ }^{40}$ Conforme o pensamento deste Autor, o tipo incriminado pela lei de lavagem é rigorosamente material e, por essa razão, exige a identificação de bens jurídicos específicos a serem protegidos, ao contrário dos delitos de mera conduta, por exemplo.

A dificuldade, no entanto, permanece, dado que o bem jurídico protegido deve ser apreendido de forma mediata, abarcando vários objetivos do legislador: por um lado, os delitos antecedentes devem deixar de ser rentáveis ao seu Autor, que, idealmente, restaria isolado com os produtos da ação criminosa; por outro lado, e paralelamente, a suspeita da prática de uma ação delitiva deve ser aproveitada para elucidar e aniquilar estruturas criminosas de forma a impedir a realização de novas práticas criminosas por referidas organizações.

Esta postura é assumida, dentre outras, por boa parte das doutrinas alemã ${ }^{41} \mathrm{e}$ suíça, ${ }^{42}$ em cujas codificações o tipo de lavagem encontra-se inserido, não junto à proteção à ordem econômica, mas, sim, ao lado dos crimes contra a administração da justiça, o que justifica tal interpretação.

Do ponto de vista da legislação brasileira, no entanto, se o bem jurídico administração da justiça fosse admitido como o protegido pelo crime de lavagem de dinheiro, argumenta-se que este se aproximaria muito do tipo penal do favorecimento real, ${ }^{43}$ estabelecido no Código Penal, art. 349, e, nesse caso, a aplicabilidade da lei ficaria limitada da mesma maneira como no caso de se reconhecer uma "superproteção" do bem jurídico dos delitos prévios, dado que, também na hipótese do favorecimento real, o autor, cúmplice ou partícipe do crime anterior não pode ser punido também pelo delito de favorecimento. ${ }^{44}$ Ademais, o estudo do tipo do favorecimento, no Direito brasileiro, demonstra que as formas de lavagem de dinheiro descritas na Lei n. 9.613/1998

${ }^{40}$ HEFENDEHL, Roland. op. cit., p. 152. No mesmo sentido, v. SALDITT, Franz. op. cit., p. 122.

${ }^{41}$ Segundo W. Bottke, os criadores da lei de prevenção e combate alemã afirmavam que o bem jurídico protegido pelo $\S 261$ do StGB seria, exclusivamente, a administração da justiça ("Rechtspflege") em sua função específica de afastar os efeitos decorrentes de delitos. (BOTTKE, Wilfried. op. cit., p. 123.)

${ }^{42}$ Conforme destaca J. Natterer (NATTERER, Judith. Money-laundering and forfeiture legislation in Switzerland. European Journal of Crime, Criminal Law and Criminal Justice, v. 5, p. 220-227, 1997. p. 222.)

43 PODVAL, Roberto. O bem jurídico do delito de lavagem de dinheiro. Revista Brasileira de Ciências Criminais, São Paulo, v. 6, n. 24, p. 209-222, out./dez. 1998. p. 219; CALLEGARI, André Luís. Lavagem de dinheiro. cit., p.146.

44 PITOMBO,Antônio Sérgio A. de Moraes. Lavagem de dinheiro: a tipicidade do crime antecedente. São Paulo: Revista dos Tribunais, 2003. p. 75-76; CALLEGARI, André Luís. Lavagem de dinheiro. cit., p.146. Este autor também inclui entre os tipos que passariam a se confundir com o crime de lavagem de dinheiro o favorecimento pessoal (Código Penal, art. 348). 
não tipificam condutas dessa natureza, apesar de, à primeira vista, poderem parecer semelhantes. A realização de condutas enunciadas na tipificação do crime de lavagem de dinheiro não induz nenhum ataque ao bem jurídico administração da justiça, o que leva à conclusão de que essas condutas possuem uma tipificação diferente da do favorecimento, causando lesão a outro bem jurídico. ${ }^{45}$

Ademais, entende-se que, por mais que o efeito da lavagem de dinheiro sobre a administração da justiça seja relevante, é apenas reflexo, devendo-se levar em conta a atividade da comunidade internacional no sentido de minimizá-lo por meio de tratados e acordos internacionais de cooperação judiciária em matéria penal. ${ }^{46}$

\subsection{A Ordem Econômica}

Outra - bem mais aceita - construção doutrinária é a atinente à proteção da ordem econômica. Conforme esse entendimento, a lavagem de dinheiro atinge diretamente a ordem socioeconômica da comunidade em que se realiza, uma vez que os valores assim incorporados à economia local e nacional são misturados indiscriminadamente com valores lícitos, gerando uma aparente riqueza. No entanto, nada é, de fato, produzido, razão pela qual também não são gerados novos empregos, investimentos etc., e o aparente crescimento na economia beneficia apenas poucas pessoas.

Devido às graves conseqüências decorrentes para o sistema econômico (entre elas, por exemplo, o comprometimento do fluxo regular de capitais, a concorrência desleal, o surgimento de monopólios, a falta de transparência de operações financeiras, o abuso do poder econômico, a facilitação da corrupção), parcela considerável da doutrina entende que a lavagem de dinheiro constitui um tipo penal que afronta a segurança e o regular funcionamento da ordem econômica e financeira em todos os seus aspectos..$^{47 / 48}$

${ }^{45}$ CALlEGARI, André Luís. Lavagem de dinheiro. cit., p.146-147.

${ }^{46}$ Entre tais acordos, vale destacar os seguintes, firmados pelo Brasil: com os EUA, o "Acordo de Assistência Judiciária em Matéria Penal", no âmbito do MERCOSUL, o "Protocolo de Assistência Jurídica Mútua em Assuntos Penais", e com a Suíça, o "Tratado de Cooperação Jurídica em Matéria Penal”, entre outros com diversos países da América Latina e da Europa.

${ }^{47}$ CERVINI, Raúl; OLIVEIRA, Willian Terra de; GOMES, Luiz Flávio. Lei de lavagem de capitais. São Paulo: Revista dos Tribunais, 1998. p. 321. Segundo CALLEGARI, André Luís. Lavagem de dinheiro. cit., p. 140141, isso decorreria do fato de os capitais ilícitos arcarem, no total, com menos custos do que os capitais lícitos, que são obrigados a adquirir insumos e realizar investimentos ao custo do mercado, enquanto os capitais ilícitos enfrentam custos notoriamente inferiores.

${ }^{48}$ Nesse sentido, emerge novamente a relevância da ligação entre a criminalidade organizada e o delito de lavagem de dinheiro uma vez que "no exercício da atividade empresarial, o crime organizado acaba adotando práticas que atingem a livre-iniciativa, a propriedade, a concorrência, o consumidor, o meio ambiente, o patrimônio histórico, enfim, vários aspectos da ordem socioeconômica", conforme ressalta PITOMBO, 
A maior parte da doutrina brasileira inclina-se para a aceitação da ordem econômica como bem jurídico protegido pela Lein. 9.613/1998. ${ }^{49} \mathrm{Nesse}$ sentido, argumentase que, ainda que, por vezes, se identifique uma série de interesses, inclusive individuais, lesados pela conduta do agente que comete a lavagem de dinheiro, o objetivo desta norma é a proteção dos interesses globais e da finalidade individual de normalidade da ordem social e econômica. ${ }^{50}$ Sob esse prisma supraindividual adotado pela doutrina brasileira majoritária afirma-se que os interesses individuais atingidos estariam todos apoiados no substrato da ordem econômica nacional, de forma que a proteção desta acarretaria a proteção daqueles, razão pela qual também não surpreende a criação de novos tipos protetores da ordem econômica, em geral sob a forma de crimes de perigo abstrato. ${ }^{51}$

Em sentido contrário, Ela Wiecko de Castilho afirma que os mercados internacionais não repudiam, por completo, a presença dos ativos ilícitos. ${ }^{52 / 53}$ Do mesmo modo, Manfred Maiwald apresenta o argumento de que dificilmente se poderia apresentar uma oposição ao emprego no mercado lícito de recursos oriundos de atividades criminosas do ponto de vista puramente econômico; ${ }^{54}$ isso somente poderia ser reprovado do ponto de vista moral. Na mesma esteira, Roland Hefendehl argumenta que a confiança na ordem econômica não poderia ser tida como o bem jurídico neste caso porque, ao invocar o conceito de "confiança" para a definição de um dado bem, torna-se necessária a

Antônio Sérgio A. de Moraes. op. cit., p. 79. No mesmo sentido, CERVINI, Raúl; OLIVEIRA, Willian Terra de; GOMES, Luiz Flávio. op cit., p. 314.

${ }^{49}$ PITOMBO, Antônio Sérgio A. de Moraes. op. cit., p. 77.

${ }^{50}$ CALLEGARI, André Luís. Lavagem de dinheiro. cit., p. 142.

${ }^{51}$ Atente-se, no entanto, para o fato de que, em 1982, a Associação Internacional de Direito Penal, estipulou várias Resoluções, entre elas a de n. 8, que determina que “(...) os crimes de perigo abstrato (...) são meios válidos de combate à criminalidade econômica desde que a conduta proibida seja claramente definida pelo legislador e se relacione diretamente com interesses protegidos claramente identificados" (SILVEIRA, Renato de Mello Jorge. Direito penal supra individual. cit., p. 145), sendo notável que esta identificação clara não ocorre nos dispositivos da Lei n. 9.613/1998, razão pela qual nos deparamos com a presente discussão doutrinária em âmbito mundial.

${ }^{52}$ CASTILHO, Ela Wiecko de. Crimes antecedentes e lavagem de dinheiro. Revista Brasileira de Ciências Criminais, São Paulo, v. 12, vn 47, p. 46-59, mar./abr. 2004. p. 53 e ss. O mesmo argumento é apresentado por GRECO FILHO, Vicente. op. cit., p. 161-162.

${ }^{53}$ Interessante notar, na doutrina espanhola, que M. Cobo del Rosal e C. Z. López-Gómez, se aproximam dessa teoria, ao afirmar que "El orden socioeconómico, es lo único que podría, per no, necesariamente, verse alterado por el delito de blanqueo de capitales aunque no en su conjunto". No entanto, destaca-se que esses autores defendem que o delito da lavagem de dinheiro, não deveria ser tratado pelo direito penal, mas sim como infração administrativa. (COBO DEL ROSAL, Manuel; LÓPEZ-GÓMEZ, Carlos Zabala. op. cit., p. 94).

${ }^{54}$ MAIWALD, Manfred. Auslegungsprobleme im Tatbestand der Geldwäsche. In: WEIGEND, T.; KÜPPER, G. (Orgs.). Festschrift für Hans Joachim Hirsch zum 70. Geburtstag am 11. april 1999. Berlim / Nova Iorque: Walter de Gruyter, 1999. p. 633. 
existência da possibilidade de opção pela sociedade. Em se tratando da ordem econômica, é impossível vislumbrar a opção da sociedade por outra alternativa que forneça segurança na mesma seara. ${ }^{55}$

Particularmente na América Latina, no entanto, os Estados passaram a identificar a lavagem de dinheiro como uma das causas a dificultar a atração e manutenção de investimentos estrangeiros lícitos nos países, conscientizando-se da corrosão e do abalo que sofrem os seus mercados e sistemas econômicos em decorrência da circulação de capitais ilegítimos. ${ }^{56}$ Nesse sentido, parcela da doutrina chega a equiparar a defesa da ordem econômica com a defesa do Estado $^{57}$ face à potencialidade de os crimes tidos como antecedentes à lavagem de dinheiro gerarem lucros tão vultosos e ingerências tão profundas na ordem política que poderiam levar a instabilidades até de governos, razão pela qual a Lei n. 9.613/1998 tutelaria, objetivamente, o Sistema Financeiro Econômico Nacional. ${ }^{58}$

Isso também decorre da identificação dos problemas causados pela injeção de capitais ilícitos na economia formal dos países selecionados para essa atividade criminosa: os fluxos de capitais, via de regra, acabam contrariando as chamadas leis econômicas, dado que buscam deixar países com políticas econômicas sólidas (e conseqüentes controles rigorosos) para buscar refúgio em regiões onde as políticas econômicas são frágeis e as taxas de retorno de investimentos mais baixas do que as que poderiam ser obtidas em países tidos como sólidos. Indubitavelmente, num primeiro momento, o ingresso do capital (de qualquer origem) parece “enriquecer" a economia local: no entanto, no caso dos capitais oriundos dos crimes tidos como antecedentes em qualquer lugar no mundo, estes apenas ingressam na economia formal de um país, a fim de poderem dela se retirar quando melhor aprouver e com a aparência de licitude, tratando-se, portanto, de capitais de alta volatilidade, refletida nas oscilações de taxas de câmbio, preços de determinados bens no mercado etc., fragilizando a economia do país em que ingressam.

Esse cenário afigura-se tanto mais preocupante, na medida em que é possível verificar que as grandes organizações criminosas dispõem de tamanha disponibilidade de

\footnotetext{
${ }^{55}$ HEFENDEHL, Roland. op. cit., p. 151.

${ }^{56}$ Nesse sentido, v. PITOMBO, Antônio Sérgio A. de Moraes. op. cit., p. 80-83.

${ }^{57}$ Conforme, por exemplo, T. I. Odon, a “'defesa de uma economia saudável' não deixa de ser uma 'defesa da sociedade civil', credora do Estado, e, assim, 'defesa do governo', 'defesa da política'. Em última instância, se estamos falando de condutas criminosas que lidam com a moeda, não existe diferença prática entre 'defesa da economia' e 'defesa do Estado'.” (ODON, Tiago Ivo. op. cit., p. 336).

58 COSTA, Hekelson Bitencourt Viana da. Lavagem de dinheiro - Lei n. 9.613/98. Revista Ibero-Americana de Direito Público, Rio de Janeiro, ano III, n. 11, jul./dez. 2003. p. 118.
} 
bens e dinheiro, provenientes de atividades criminosas e, portanto, com total liquidez, que o seu reinvestimento pode gerar desvios e condicionamentos no mercado financeiro, a ponto de poder levar ao controle de um inteiro ramo econômico. ${ }^{59}$

As particularidades da construção típica do crime de lavagem de dinheiro, especialmente as condutas envolvendo tecnologias de comunicação modernas, típicas da sociedade pós-industrial, demonstram que a atividade do agente da lavagem de dinheiro coloca em risco interesses individuais e da sociedade como um todo, podendo ocorrer grave desestabilização de todo o sistema financeiro e da ordem econômica nacional, inviabilizando o desenvolvimento do próprio país face à dimensão tomada pelo delito. Isso impõe a sua qualificação como um tipo penal destinado a proteger um bem jurídico supraindividual considerado em campo difuso, ${ }^{60}$ sendo esta a maior das justificativas para a adoção da ordem econômica como o bem jurídico tutelado.

Nesse sentido, conforme também ressalta Tiago Ivo Odon, uma das particularidades do crime de lavagem de dinheiro é a produção de efeitos difusos por toda a sociedade, sendo certo que "ele afeta tanto o Estado quanto o cidadão comum". ${ }^{61}$

Tendo, de modo geral, estabelecido a ordem econômica como o bem jurídico protegido pela Lei n. 9.613/1998, a doutrina brasileira vem começando a debater a questão em torno da definição quanto às pessoas e, especificamente, às atividades que podem, efetivamente, ser sujeitos ativos ou, respectivamente, possibilitar o cometimento do crime de lavagem de dinheiro, preocupando-se, entre outros, com a posição do advogado, cuja atividade tem sido objeto de preocupação e alvo de discussões no Exterior, particularmente na Alemanha, onde a problemática já foi analisada detalhadamente duas vezes por tribunais superiores distintos daquele país. ${ }^{62}$ No entanto, essas novas discussões têm enfrentado grandes dificuldades justamente diante do fato de que esta determinação do bem jurídico contraria vários argumentos apresentados na própria doutrina, além de

59 COSTA, José de Faria. O branqueamento de capitais: algumas reflexões à luz do direito penal e da política criminal). In: CORREIA, Eduardo, et al. Direito penal económico europeu: Textos doutrinários. Problemas especiais. Coimbra: Coimbra Editora, 1999. p. 306.

${ }^{60}$ Ressalte-se que "interesses difusos dizem respeito a uma valoração de pessoas e valores genéricos, pessoas e interesses em massa, conflitando entre si. Esses interesses difusos propriamente ditos têm seu vínculo entre pessoas e os fatos conjunturais genéricos. Têm a característica, ainda, de pautarem-se em dados de fato acidentais e mutáveis, pois se referem, no geral, à qualidade de vida." (SILVEIRA, Renato de Mello Jorge. Direito penal supra individual. cit., p. 61.)

${ }^{61}$ ODON, Tiago Ivo. op. cit., p. 348.

62 Destacam-se as seguintes decisões: OLG Hamburg 2 Ws 185/99; BGH 2 StR 513/00; 2 BvR 1520/01; 2 BvR 1975/03. No Brasil, A. L. Callegari tratou de problemática análogo relativamente à atividade de agentes financeiros. (CALLEGARI, André Luís. Participação (punível?) de agentes financeiros no delito de lavagem de dinheiro. Revista dos Tribunais, São Paulo, v. 92, n. 815, p. 464-475, abr. 2002). 
parecer não levar em conta todos os aspectos relevantes envolvendo as relações sociais fáticas que justificam essa proteção penal.

Assim, deve ser destacado que parcela pequena da doutrina, na qual se destaca Roberto Podval, não admite a ordem econômica como o bem jurídico protegido pela legislação de prevenção e combate à lavagem de dinheiro, sob o argumento de que "o bem jurídico não pode, nem deve ser admitido de forma tão genérica, sob pena de, indiretamente, extinguir-se a garantia que o bem jurídico oferece" ${ }^{63}$ Segundo esse Autor, a ordem econômica não poderia ser tida como um bem jurídico em si mesmo, mas sim, como um feixe da vida em sociedade, regulado por normas previstas constitucionalmente, e apenas estas poderiam, possivelmente, ser dignas de tutela penal. Em resposta às críticas desse gênero, alguns autores restringem esse bem jurídico para abranger apenas um aspecto que seria ferido pela lavagem de dinheiro. ${ }^{64}$

\section{Conclusão}

Diante do exposto, torna-se evidente que o problema suscitado para este estudo está longe de ser resolvido. Assim, por mais que os argumentos teóricos, hoje, nos levem a crer que o bem jurídico efetivamente protegido pelo delito de lavagem de dinheiro seja a ordem econômica, outras dúvidas se apresentam. Por exemplo - ao buscar imaginar a ocorrência de uma lesão à ordem econômica que efetivamente fosse sentida pela sociedade - não se pode deixar de perquirir pelo montante de bens e valores que necessariamente teriam de ser lavados para desestabilizar a ordem econômica de um país, mesmo em se tratando de países em desenvolvimento, principalmente tendo em vista que a lavagem de capitais também é possível sem qualquer envolvimento de estabelecimentos financeiros ou potencial ameaça à ordem econômica, conforme destaca Lars Hombrecher. ${ }^{65}$

Pergunta-se, ademais, se não têm mais razão os economistas quando afirmam que a origem do capital que transita pela economia é indiferente e que ela se mantém, em muito, justamente em função do próprio fluxo de valores, investimentos etc. Não se estaria, então, na verdade, mais diante uma tentativa de moralização do mercado ao invés de uma verdadeira sua proteção?

${ }^{63}$ PODVAL, Roberto. op. cit., p. 213.

${ }^{64}$ Assim, por exemplo, para BOTTKE, Wlfried. op. cit., p. 123 ss., o bem jurídico protegido seria a livre concorrência, como pressuposto para o funcionamento regular da economia.

${ }^{65}$ HOMBRECHER, Lars. Geldwäsche (\$ 261 StGB) durch Strafverteidiger?: Eine Untersuchung zur Anwendung des $§ 261$ StGB auf das Honorar des Strafverteidigers. Aachen: Shaker, 2001. p. 119. 
E quanto aos defensores da tese de que o bem jurídico protegido seria a administração da justiça, no sentido da quase absoluta instrumentalização do tipo penal da lavagem de dinheiro e seu emprego na persecução dos crimes antecedentes: se este fosse o objetivo exclusivo do legislador, não seria mais adequado e eficaz simplesmente implementar controles rigorosos em âmbito administrativo, como sugerem Manuel Cobo del Rosal e Carlos Zabala López-Gómez, ao defender que o delito da lavagem de dinheiro não deveria ser tratado pelo Direito Penal, mas sim como infração administrativa, por meio de cujas (gravosas) multas, seria mais fortemente desencorajado, afirmando que "el llamado delito de blanqueo de capitales, sencillamente, no debiera ser delito, en su caso infracción administrativa, y a lo sumo delito fiscal se después de blanquearlo no se declara a Hacienda Pública como es lógico y natural. Sólo el dislocado y poco inteligente afán represivo contra el narcotráfico, terrorismo y la criminalidad organizada, ha llevado a la configuración como un delito con pena criminal, en lugar de que se fuese una mera infracción administrativa con una simples aunque grave multa". ${ }^{66}$

Transferido para o âmbito administrativo, ter-se-ia solucionado o problema, uma vez que seria possível implementar todos os controles regulatórios necessários para fiscalizar a origem dos valores utilizados na vida econômica, quanto estes controles alertariam para a realização de outras atividades ilícitas, de modo a auxiliar, instrumentalmente, a administração da justiça na persecução dos crimes antecedentes. Ademais, a regulamentação da origem dos recursos utilizados no âmbito do Direito Administrativo permitiria uma flexibilidade muito maior ao órgão fiscalizatório do que é possível ou desejável no âmbito da Justiça Penal, de modo que o Estado se tornaria muito mais apto a acompanhar a evolução do comportamento apresentado pelos agentes dos crimes antecedentes na tentativa de ocultar a origem de seus recursos.

Diante das dificuldades que se tem encontrado para garantir a segurança jurídica ao tratar dessa conduta no âmbito do Direito Penal, talvez a descriminalização e administrativização da matéria seja o caminho que mais se coaduna com o Estado Democrático. Até porque as dificuldades que essa legislação encontrou em sua aplicação criminal já restaram amplamente comprovadas, pelo menos no Brasil, onde se verifica a ausência de acusações com base em provas sólidas e, do mesmo modo, a quase inexistência de condenações, apesar de a Lei n. 9.613/1998 já viger há quase nove anos.

Considerando a ineficácia até o momento apresentada pela referida legislação, chega-se a um ponto verdadeiramente preocupante diante da importância

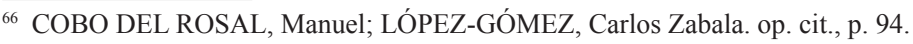


que tem sido atribuída a essa legislação: a de que ela seja somente mais um exemplo do Direito Penal simbólico, ${ }^{67}$ cada vez mais difundido na proteção dos interesses difusos das sociedades. Verdadeira falácia da atualidade, referido simbolismo, que se exprime através da criação de novos tipos penais ou do agravamento dos tipos existentes, "além de propiciar uma falsa ilusão de resolução dos problemas sociais, acaba por desvirtuar o sistema por completo. Não é compatível nem com a dogmática moderna, nem com os princípios e garantias assegurados pelo Estado Democrático de Direito" ${ }^{68}$

O simbolismo no Direito Penal, por sua vez, é duplamente grave, uma vez que demonstra a intenção meramente simbólica do legislador, que tenta transmitir à sociedade a aparência de que há uma preocupação com a sua segurança ${ }^{69}$ No entanto, nesse diapasão, acaba por inflacionar a legislação penal e acabando por, em sua incoerência, minar toda a política criminal estabelecida, a ponto de se tornar cada vez mais difícil identificar uma linha definida nesta. Essa incoerência, por sua vez, leva à perda de confiança por parte da população na Justiça Penal e, dado maior prazo, à total perda de eficácia do sistema.

Diante da gravidade dos delitos antecedentes que originaram a onda repressiva identificada por Barry Ryder como uma "crusade against money laundering", ${ }^{70}$ afigura-se como altamente preocupante que, justo em relação a delitos tidos como particularmente graves, tenha se imposto o simbolismo no afã incriminador do legislador Penal.

São Paulo, setembro de 2007.

\section{Referências}

ANDRADE, Manuel da Costa. A nova lei dos crimes contra a economia (Dec.-Lei n. 28/84, de 20 de janeiro) à luz do conceito de "bem jurídico". In: CORREIA, Eduardo, et al. Direito penal económico europeu: textos doutrinários. Problemas gerais. Coimbra: Coimbra Editora, 1998. v. 1, p. 387-411.

BARTON, Stephan. Sozial übliche Geschäftstätigkeit und Geldwäsche(§261 StGB). Strafverteidiger, ano 13, v. 3, p. 156-163, 1993.

\footnotetext{
${ }^{67}$ Essa preocupação fica nítida em PRITTWITZ, Cornelius. Die Geldwäsche und ihre strafrechtliche Bekämpfung - oder: Zum Einzug des Lobbyismus in die Kriminalpolitik. Strafverteidiger, ano 13, v. 9, p. 498-502, 1993.

${ }_{68}$ SILVEIRA, Renato de Mello Jorge. Direito penal supra individual. cit., p. 170.

${ }^{69}$ GODOY, Antonio Tide Tenório A. M. Tutela penal efetiva nos crimes contra a ordem econômica. Boletim IBCCrim, São Paulo, v. 14, n. 169, p. 14, dez. 2006.

${ }^{70}$ RYDER, Barry. op. cit., p. 681 ss.
} 
BECK, Ulrich. La sociedad del riesgo: hacia una nueva modernidad. Tradução J. Navarro, D. Jiménez, M. R. Borrás. Barcelona: Paidós, 1998.

BOTTKE, Wilfried. Teleologie und Effektivität der Normen gegen Geldwäsche (Teil 2). Zeitschrift für Wirtschaft-Steuer-Strafrecht (WISTRA), ano 14, v. 4, p. 121-130, 15 de maio de 1995.

BURR, Christian. Geldwäsche: Eine Untersuchung zu $§ 261$ StGB. Siegburg: Schmitt, 1995.

BUSTOS RAMÍREZ, Juan. Política criminal e injusto (política criminal, bem jurídico, desvalor do ato e do resultado). Tradução de J. Sérgio Fragoso. Revista de Direito Penal, Rio de Janeiro, n. 29, p. 38-54, jan./jun. 1980.

CALLEGARI, André Luís. Lavagem de dinheiro. São Paulo: Manole, 2004.

CALLEGARI, André Luís. Participação (punível?) de agentes financeiros no delito de lavagem de dinheiro. Revista dos Tribunais, São Paulo, v. 92, n. 815, p. 464-475, set. 2003.

CASTILHO, Ela Wiecko de. Crimes antecedentes e lavagem de dinheiro. Revista Brasileira de Ciências Criminais, São Paulo, v. 12, n. 47, p. 46-59, mar./abr. 2004.

CERVINI, Raúl, Oliveira, William Terra de; GOMES, Luiz Flávio. Lei de lavagem de capitais. São Paulo: Revista dos Tribunais, 1998.

COBO DEL ROSAL, Manuel; LÓPEZ-GÓMEZ, Carlos Zabala. Blanqueo de capitales: abogados, procuradores y notarios, inversores, bancarios y empresarios (Repercusión en las leyes españolas de las nuevas directivas de la Comunidad Europea) (Estudio doctrinal, legislativo y jurisprudencial de las infracciones y de los delitos de blanqueo de capitales). Madrid: CESEJ, 2005.

COSTA, Hekelson Bitencourt Viana da. Lavagem de dinheiro: lei n. 9.613/98. Revista IberoAmericana de Direito Público, Rio de Janeiro, ano III, n. 11, jul./dez. 2003.

COSTA, José de Faria. O branqueamento de capitais: algumas reflexões à luz do direito penal e da política criminal. In: CORREIA, Eduardo, et al. Direito penal económico europeu: textos doutrinários. Problemas gerais. Coimbra: Coimbra Editora, 1999. v. 2, p. 301-320.

GODOY, Antonio Tide Tenório A. M. Tutela Penal efetiva nos crimes contra a ordem econômica. Boletim IBCCrim, São Paulo, v. 14, n. 169, p. 14, dez. 2006.

GRECO FILHO, Vicente. Tipicidade, bem jurídico e lavagem de valores. In: COSTA, José de Faria; SILVA, Marco Antonio Marques da (Coords.). Direito penal especial, processo penal e direitos fundamentais: visão luso-brasileira. São Paulo: Quartier Latin, 2006. p. 147-169. 
HEFENDEHL, Roland. Kann und soll der Allgemeine Teil bzw. das Verfassungsrecht missglückte Regelungen des Besonderen Teils retten? In: Schünemann, Bernd, et al (Coords.). Festschrift für Claus Roxin sum 70. Geburtstag am 15. Mai 2001. Berlin: Walter de Gruyter, 2001.

HOMBRECHER, Lars. Geldwäsche (\$261 StGB) durch Strafverteidiger?: Eine Untersuchung zur Anwendung des $§ 261$ StGB auf das Honorar des Strafverteidigers. Aachen: Shaker, 2001.

KARGL, Walter. Probleme des Tatbestands der Geldwäsche (§ 261 StGB). Neue Justiz - Zeitschrift für Rechtsprechung und Rechtsanwendung, v. 55, v. 2, p. 57-63, 2001.

LIBERATI, Wilson Donizeti. Bem jurídico-penal e constituição. In: LOPES, Maurício Antonio Ribeiro; LIBERATI, Wilson Donizeti (Orgs.). Direito penal e constituição. São Paulo: Malheiros, 2000. p. $157-210$.

MAIA, Rodolfo Tigre. Lavagem de dinheiro: lavagem de ativos provenientes de crime - anotações às disposições criminais da Lei n. 9.613/98. São Paulo: Malheiros, 1999.

MAIWALD, Manfred. Auslegungsprobleme im Tatbestand der Geldwäsche. In: WEIGEND, T.; KÜPPER, G. (Orgs.). Festschrift für Hans Joachim Hirsch zum 70. Geburtstag am 11. april 1999. Berlim / Nova Iorque: Walter de Gruyter, 1999. p. 631-649.

NATTERER, Judith. Money-laundering and forfeiture legislation in Switzerland. European Journal of Crime, Criminal Law and Criminal Justice, v. 5, p. 220-227, 1997.

ODON, Tiago Ivo. Lavagem de dinheiro: os efeitos macroeconômicos e o bem jurídico tutelado. Revista de Informação Legislativa, Brasília, v. 40, n. 160, p. 333-349, out./dez. 2003.

PINHEIRO, Luís Goes. O branqueamento de capitais e a globalização: facilidades na reciclagem, obstáculos à repressão e algumas propostas de política criminal. Revista Portuguesa de Ciência Criminal, Coimbra, v. 12, n. 4, p. 603-648, out./dez. 2002.

PITOMBO, Antônio Sérgio A. de Moraes. Lavagem de dinheiro: a tipicidade do crime antecedente. São Paulo: Revista dos Tribunais, 2003.

PODVAL, Roberto. O bem jurídico do delito de lavagem de dinheiro. Revista Brasileira de Ciências Criminais, São Paulo, v. 6, n. 24, p. 209-222, out./dez. 1998.

PRADO, Luiz Regis. Bem jurídico-penal e constituição. São Paulo: Revista dos Tribunais, 1997.

PRITTWITZ, Cornelius. Die Geldwäsche und ihre strafrechtliche Bekämpfung - oder: Zum Einzug des Lobbyismus in die Kriminalpolitik. Strafverteidiger, ano 13, v. 9, p. 498-502, 1993. 
RYDER, Barry. The crusade against money laundering. In: Politica Criminal, Derechos Humanos y Sistemas Jurídicos en el Siglo XXI. Volumen de homenaje al prof. Dr. Pedro R. David en su 72. aniversario (21/7/1929). Buenos Aires: Depalma, 2001. p. 681-713.

SALDITT, Franz. Der Tatbestand der Geldwäsche. Strafverteidiger, v. 1, p. 121-136, 1992.

SILVEIRA, Renato de Mello Jorge. Direito penal supra-individual. São Paulo: Revista dos Tribunais, 2003.

SILVEIRA, Renato de Mello Jorge. A construção crítica do bem jurídico espiritualizado e suas críticas fundamentais. Boletim IBCCrim, São Paulo, v. 10, n. 122, p. 14-15, jan. 2003. 